\title{
Special Features of Metaplastic Breast Cancer in Tunisian Women
}

\section{Raja Briki, Ons Cherif*, Mouna Derouich, Anouar Chaieb, Sassi Boughizane, Abdeljalil Khlifi, Hedi Khairi}

Department of Gynecology and Obstetrics, Farhat Hached University Hospital, Sousse, Tunisia

Email: *onscherifb@gmail.com

How to cite this paper: Briki, R., Cherif, O., Derouich, M., Chaieb, A., Boughizane, S., Khlifi, A. and Khairi, H. (2018) Special Features of Metaplastic Breast Cancer in Tunisian Women. Open Journal of Obstetrics and Gynecology, 8, 1310-1323. https://doi.org/10.4236/ojog.2018.813133

Received: September 16, 2018

Accepted: November 5, 2018

Published: November 8, 2018

Copyright $\odot 2018$ by authors and Scientific Research Publishing Inc. This work is licensed under the Creative Commons Attribution International License (CC BY 4.0).

http://creativecommons.org/licenses/by/4.0/

\section{cc) (i) Open Access}

\begin{abstract}
Introduction: Metaplastic breast carcinomas are a rare, heterogeneous group of breast malignancies characterized by an intrinsically aggressive histology and an unfavorable prognosis. Objective: To determine the clinical and pathological characteristics of metaplastic breast cancers in Tunisian patients, and evaluate their impact on its evolution. Methods: A retrospective study of 44 cases of metaplastic cancers archived during a 26-year period in the Cancer Registry of the Tunisian Center. Results: The frequency of metaplastic cancer was $0.97 \%$. Mean age at diagnosis was 55.4 years (range 26 - 84). Average time to diagnosis was 5.5 months. Average clinical tumor size was 4.95 $\mathrm{cm}$ (range 1.5 - 15). Axillary ipsilateral adenopathy was present at diagnosis in $45.9 \%$. The clinical stages IIB (31.8\%) and IIA (22.7\%) predominated. Squamous metaplasia was the most common (68\%) followed by the heterologous mesenchymal subtype. Ganglionic invasion was histologically proven in 17 cases, of which $77 \%$ had only adenocarcinomatous contingents. Absence of hormone receptor expression and HER2 overexpression predominated. Primary surgery was carried out in $95 \%$ of cases. Average follow-up was 40 months (range 2 - 135). Average overall survival (OS) was 74 months, $63 \%$ at 5 years and $60 \%$ at 10 years. Average progression free survival (PFS) was 29 months (range 3 - 129), 38\% at 5 years and 32\% at 10 years. Factors significantly influencing OS and PFS were histological lymph node involvement ( $\mathrm{p}=0.001$ and $\mathrm{p}=0.002$ respectively). Conclusion: Metaplastic breast cancer observed in Tunisian women constitutes a histological type with an unfavorable prognosis whose improvement requires a more adapted therapeutic strategy.
\end{abstract}

\section{Keywords}

Breast, Metaplastic Cancer, Pathology, Prognosis 


\section{Introduction}

Metaplastic breast carcinomas are rare and form a heterogeneous group of tumors characterized by a histological definition associating an adenocarcinomatous component with an epidermoid, sarcomatoid, chondroid or osteoid contingent [1]. The definitions are based on the possible metaplasia of a cell (of controversial, epithelial, myoepithelial, or totipotent reserve origin) into another type of epithelial or mesenchymal cell.

Frequency of metaplastic carcinomas is estimated at less than $1 \%$ of all malignant tumor pathology of the breast. These tumors are generally of high grade and have a poorer prognosis than classical ductal carcinomas.

Described for the first time by Huvos et al. in 1973 [2], they form a separate pathological entity [3] [4], whose frequency is estimated between $0.25 \%$ and $1 \%$ of breast cancers [3] [4].

The purpose of this study was to determine the clinical and pathological characteristics of this type of breast cancer in the Tunisian population, and to assess its impact on further disease evolution. Our research question was: what clinical and histological specificities can be attributed to this uncommon type of breast cancer in our Tunisian patients? And what would be the influence of these properties on its evolutionary prognosis?

\section{Methods}

In this study, we retrospectively reviewed and analyzed all cases of breast cancer diagnosed from January 1987 until December 2012, and particularly all cases of metaplastic carcinoma archived during this period in the Cancer Registry of the Tunisian Center.

All patients included in this study had metaplastic breast carcinoma.

Diagnosis is based on the anatomopathological study. It contained low-grade adenosquamous carcinoma, fibromatosis-like metaplastic carcinoma, squamous cell carcinoma, spindle cell carcinoma, metaplastic carcinoma with mesenchymal differentiation, mixed metaplastic carcinoma, and myoepithelial carcinoma (according to the World Health Organisation (WHO) classification of breast tumour 2012).

In practice, different metaplastic aspects are often entangled, and the differences between all these entities are often not very explicit, making these classifications difficult to apply.

So, in our study, we opted for a simplified classification according to the type of metaplasia encountered: squamous cell, spindle cell (expressing cytokeratin) and heterologous mesenchymal cells.

We were able to identify 44 cases. All cases of cancer were treated and followed in the Departments of Gynecology and/or Medical Oncology and Radiotherapy of the Farhat Hached University Hospital in Sousse, Tunisia.

Data were collected from patients' clinical records and pathology reports. In all cases, we specified the age at diagnosis, history of cancer, menopausal status, 
discovery circumstances, physical examination data (tumor size, location, TNM classification...), anatomopathological result (histological size, type of the metaplastic component, Scarff Bloom and Richardson score (SBR), lymph node status, ...) and immunohistochemical study (hormonal status, expression of the HER2 oncoprotein) as well as the evolutionary data.

For the survival analysis, we used data from medical records. Patients lost to follow-up were contacted, and for cases that were not available, we consulted the national register of deaths.

Data entry was done with the Chi2 test on the SPSS computer program version 18.0. For the comparison of variables, it was assumed that the correlation is significant for a probability rate greater than $95 \%(\mathrm{p}<0.05)$. Univariate analysis of overall survival and progression free survival was carried out according to different parameters (age, clinical stage, location and certain histological factors).

The survival analysis was performed using the Kaplan-Meier method. The links between the variables and survival were analyzed by log-rank test. The statistical significance was set at $5 \%$.

\section{Results}

Forty-four cases of metaplastic carcinoma were found in the records of a total of 4516 breast cancers, or a frequency of $0.97 \%$ during the study period.

All metaplastic carcinoma patients were female. The average age at diagnosis was 55.4 years with extremes ranging from 26 to 84 years.

A history of breast cancer in first and second degree parents (mother, sister, daughter, cousin, niece) was noted in 10 patients, but without specifying the histological type.

None of our patients had a personal history of cancer. However, a personal history of benign breast lesions such abscesses ( 2 cases), fibroadenoma (1 case) and non-proliferative cystic mastopathy ( 1 case) was found.

The majority of our patients (75\%) were multiparous (3rd par and more); most had breastfed their children (86.4\% of cases). Nulliparous women accounted for only $11.3 \%$ of cases.

Postmenopausal patients accounted for more than half of cases, or $61.4 \%$.

The average time between onset of symptoms and diagnosis was 5.5 months with extremes ranging from 2 weeks to 3 years.

A breast nodule was the main reason for consultation (54.5\% of cases).

The tumor affected the left breast in $56.8 \%$ and the right one in $43.2 \%$.

The super-external quadrant was the most affected (38.6\%), and no case of bilaterality was found.

The average clinical tumor size at the time of diagnosis was $4.95 \mathrm{~cm}$ with extremes ranging from $1.5 \mathrm{~cm}$ to $15 \mathrm{~cm}$.

For the clinical lymph node status, ipsilateral axillary lymphadenopathy was found at the time of diagnosis in $45.9 \%$. 
Mammography was performed in $68 \%$ of cases. Its s appearance was often in favor of malignancy; it was a speculative, poorly limited image with micro-calcifications. In most cases, lesions were classified as ACR4 or ACR5. However, there were images suggestive of benign lesions in three cases, two in favor of phyllode tumor and one in favor of galactocele.

Breast ultrasound was performed in $36.6 \%$ of cases; it was often a suspicious heterogeneous hypoechoic lesion with oedematous infiltration of subcutaneous fat.

A complete extension assessment was performed in $88.6 \%$ of cases. It revealed metastases from the start in $9 \%$ of cases $(n=4: M 1)$. These were bone metastases ( 2 cases) and liver metastases ( 2 cases). It was negative in $79.5 \%$ of cases ( $n=35$ : $\mathrm{M} 0)$. Staging was incomplete or unspecified in five patients $(\mathrm{Mx})$.

Concerning the TNM clinical stage, a predominance of stage IIB (31.8\%) and stage IIA (22.7\%) was noted (Table 1$)$.

The average tumor size was $4.5 \mathrm{~cm}$ (range: $1.5-12 \mathrm{~cm}$ ).

Histopathological subtypes were varied: squamousmetaplasia ( $\mathrm{n}=30,68 \%$ ), mesenchymal heterologous $(n=9)$, spindle cell metaplasia $(n=1)$, and mixed $(n$ $=4)$.

The majority of cases were SBR III (89\%). Tumor necrosis was observed in $63 \%$ of lesions, vascular emboli in $23 \%$, and peri-nerve infiltrations were reported in $4 \%$ of cases. Intra-ductal component was associated in $40 \%$ of cases.

For 31 patients who underwent axillary lymph node dissection, metastases were histologically proven in 17 cases (54\%). In $77 \%$ of the cases (13/17), only the adenocarcinomatous contingent was observed in the lymph nodes.

Immunohistochemical (IHC) study of estrogen (RO) and progesterone (RP) receptors was performed in 37 cases, and showed no expression of hormone receptors in $92 \%$ of, and OR and RP were only expressed in three cases.

Only 26 cases benefited from a HER2 status study, of which 22 (85\%) showed no HER2 overexpression (score $=0$ ), and overexpression of HER2 oncoprotein $($ score $=3)$ found only in four cases.

As a result, among the cases that benefited from an IHC study of hormone

Table 1. Case distribution by clinical stage (TNM).

\begin{tabular}{cc}
\hline Stage $\{$ TNM (number of cases)\} & Number of cases (\%) \\
\hline I $\{$ T1N0M0 $(2)\}$ & $2(4.5 \%)$ \\
IIA $\{$ T1N1M0(1); T2N0M0(9)\} & $10(22.7 \%)$ \\
IIB $\{$ T2N1M0(11); T3N0M0(3)\} & $14(31.8 \%)$ \\
IIIA $\{\mathrm{T} 3 \mathrm{~N} 1 \mathrm{M} 0(2)\}$ & $2(4.5 \%)$ \\
IIIB $\{\mathrm{T} 4 \mathrm{~N} 0 \mathrm{M} 0(2) ; \mathrm{T} 4 \mathrm{~N} 1 \mathrm{M} 0(4) ; \mathrm{T} 4 \mathrm{~N} 2 \mathrm{M} 0(1)\}$ & $7(15.9 \%)$ \\
IIIC $\{$ all TN3M0 $(0)\}$ & 0 \\
IV $\{$ all TNM1 $(4)\}$ & $4(9 \%)$ \\
Undetermined & $5(11.7 \%)$
\end{tabular}


receptors and HER2 (26/44), triple negative profile defined by non-expression of the three markers (RO-, RP- and HER2-) was found in 73\% of cases (19/26).

Surgical treatment was proposed in first intention in most of our patients (95\% of cases), with lumpectomy in 4 cases (9\%), modified radical mastectomy in 28 cases (66\%), lumpectomy followed by mastectomy in 3 cases (7\%) and simple mastectomy in 7 cases (16\%).

Chemotherapy was indicated in 37 patients. Protocols used were: FEC (Epiadriamycin, Endoxan, 5-fluorouracil (5FU)), FAC (5FU, Adriamycin, Endoxan), EMF (Epiadriamycin, Methotrexate, 5FU) and CMF (Methotrexate, Endoxan, $5 \mathrm{FU})$. It was adjuvant in 22 cases (60\%), neoadjuvant in 11 cases (30\%), neoadjuvant and adjuvant in 4 cases (10\%).

Locoregional radiotherapy was used in 21 patients (48\%).

Hormone therapy was started in 10 cases $(23 \%)$. It was prescribed for a curative purpose as an adjunctive indication in nine patients, and palliatively in a patient with stage IIIB breast carcinoma.

Duration of follow-up was from 2 months to 135 months with an average of 40 months. Post-treatment follow-up data were available for 39 patients. Five patients were lost to follow-up.

During follow-up, evolutionary events were observed in $52 \%$ of cases $(n=23)$ within a period of 3 to 96 months after starting treatment. This was a progressive continuation with distant metastasis occurring in 12 of our patients classified $\mathrm{M} 0$ at the time of diagnosis and 3 cases classified Mx. Appearance of clinically detected metastatic lymphadenopathy was noted in 8 cases: ipsilateral supraclavicular in 6 cases and contralateral supraclavicular in one case. Contralateral axillary lymph node involvement was observed in 4 cases. Adenopathies were bilateral in 2 patients.

Locoregional recurrences were noted in 9 patients undergoing optimal locoregional and systemic treatment. It was a local recurrence at the level of the scar in 7 cases and in the contralateral breast in 2 cases. Over $36 \%$ of our patients died $(\mathrm{n}=16)($ Table 2).

Table 2. Summarizes the various evolutionary events in post-therapy.

\begin{tabular}{ccccc}
\hline Case & Initial clinical stage & Treatment received & $\begin{array}{c}\text { Metastasis or } \\
\text { recurrence seat }\end{array}$ & $\begin{array}{c}\text { Time of } \\
\text { appearance } \\
\text { (months) }\end{array}$ \\
\hline 3 & IIB (T2N1M0) & MRM + RT + adj CT & LM + Cerebrum & 3 \\
6 & IIIA (T3N1M0) & Neoadj CT + MRM & LM + Pleurisy & 3 \\
7 & IIA (T2N0M0) & MRM & Pulm & 48 \\
10 & IIB (T2N1M0) & Lumpectomy + adj CT + RT & LM + GG & 25 \\
12 & IIA (T2N0M0) & MRM & Bone + Liver & 9 \\
18 & IIB (T2N1M0) & MRM + RT+ adj CT + & Lolvadex + GG & 12 \\
\hline
\end{tabular}




\section{Continued}

\begin{tabular}{|c|c|c|c|c|}
\hline 24 & $\begin{array}{l}\text { Undetermined } \\
(\mathrm{T} 4 \mathrm{bN} 1 \mathrm{Mx})\end{array}$ & Neoadj CT + MRM & $\mathrm{LM}+$ Pulm + Bone & 4 \\
\hline 26 & IIA (T1N1M0) & Lumpectomy + adj CT & Bone & 7 \\
\hline 27 & IIA (T2N0M0) & $\mathrm{MRM}+\mathrm{RT}+\operatorname{adj} \mathrm{CT}$ & Contralateral & 96 \\
\hline 28 & IIIB (T4bN1M0) & Neoadj CT + MRM + adj CT & Supraclavicular & 24 \\
\hline 29 & IIA (T2N0M0) & $\mathrm{MRM}+\mathrm{RT}+\operatorname{adj} \mathrm{CT}$ & GG + Bone + Pulm & 12 \\
\hline 30 & IIIB (T4bN1M0) & $\begin{array}{c}\text { Neoadj CT + MRM + RT + } \\
\text { Nolvadex }\end{array}$ & $\mathrm{LM}+$ Bone & 9 \\
\hline 31 & IV (T4bN1M1) & Neoadj CT + MRM & Supraclavicular & 8.5 \\
\hline 32 & IIIB (T4bN2M0) & $\begin{array}{c}\text { Neoadj CT + MRM + adj CT } \\
+ \text { Nolvadex }\end{array}$ & LM & 12 \\
\hline 33 & IIA (T2N0M0) & MRM + adj CT + Nolvadex & Pulm & 36 \\
\hline 35 & IIIA (T3N1M0 & $\begin{aligned} \text { Neoadj CT } & + \text { MRM }+ \text { adj } C T \\
& + \text { RT }\end{aligned}$ & $\begin{array}{l}\text { GG + Larcinomatous } \\
\text { lymphangitis + Pulm }\end{array}$ & 7 \\
\hline 36 & IIA (T2N0M0) & $\mathrm{MRM}+\operatorname{adj} \mathrm{CT}+\mathrm{RT}$ & Contralateral & 48 \\
\hline 37 & IIB (T2N1M0) & $\begin{array}{c}\text { MRM + adj CT + RT + } \\
\text { Nolvadex }\end{array}$ & Pleurisy & 26 \\
\hline 39 & $\begin{array}{l}\text { Undetermined } \\
\text { (T2N0Mx) }\end{array}$ & $\begin{array}{c}\mathrm{MRM}+\operatorname{adj} \mathrm{CT}+\mathrm{RT}+ \\
\text { Nolvadex }\end{array}$ & $\begin{array}{l}\text { Supraclavicular }+ \\
\text { Cerebrum }\end{array}$ & 24 \\
\hline 40 & IIA (T2N0M0) & Lumpectomy + RT & Bone & 45 \\
\hline 41 & IIB (T2N1M0) & $\mathrm{MRM}+\operatorname{adj} \mathrm{CT}+\mathrm{RT}$ & Pleurisy & 18 \\
\hline 43 & $\begin{array}{l}\text { Undetermined } \\
(\mathrm{T} 4 \mathrm{~d} \mathrm{~N} 1 \mathrm{Mx})\end{array}$ & Neoadj CT + Mastectomy & Pulm & 9 \\
\hline
\end{tabular}

Modified radical mastectomy: MRM; Radiation therapy: RT; Chemotherapy: CT; Adjuvant: adj; Neoadjuvant: Neoadj; Local metastasis: LM; Ganglionic metastasis: GG; Pulmonary: Pulm.

The average overall survival (OS) available for 37 patients was 74 months. It was $63 \%$ at 5 years and $60 \%$ at 10 years.

The average progression free survival (PFS) available for 32 patients was 29 months with extremes ranging from 3 to 129 months. PFS at 5 years and 10 years was $38 \%$ and $32 \%$ respectively.

Analysis of different clinical and pathological parameters studied did not reveal any significant difference depending on the presence or absence of a metaplastic mesenchymal component, with the exception of an association between the presence of a mesenchymal component and the occurrence of breast cancer in women at menopause $(\mathrm{p}=0.04)$.

Another significant association was found between the presence of a mesenchymal component and the localization of cancer in the right breast $(\mathrm{p}=0.03)$.

Table 3 summarizes the anatomo-clinical and evolutionary characteristics of metaplastic breast cancers according to the presence or absence of a mesenchymal contingent.

Statistical analyses of OS and PFS according to different clinical and pathological parameters are summarized in Table 4. 
Table 3. Anatomical and progressive characteristics of metaplastic breast carcinoma.

\begin{tabular}{|c|c|c|c|}
\hline \multirow{2}{*}{$\begin{array}{l}\text { Clinico-pathological } \\
\text { parameters }\end{array}$} & \multicolumn{2}{|c|}{ Metaplastic Mesenchymal Component } & \multirow[b]{2}{*}{$\mathrm{p}$ value } \\
\hline & Present $(n=11)$ & Absent $(n=33)$ & \\
\hline \multicolumn{4}{|l|}{ Age } \\
\hline$<50$ years & 6 & 11 & \multirow{2}{*}{0.28} \\
\hline$>50$ years & 5 & 22 & \\
\hline \multicolumn{4}{|l|}{ Menopause } \\
\hline Yes & 7 & 10 & \multirow{2}{*}{0.04} \\
\hline No & 4 & 23 & \\
\hline \multicolumn{4}{|l|}{ Family history of cancer } \\
\hline Yes & 3 & 7 & \multirow{2}{*}{0.69} \\
\hline No & 8 & 26 & \\
\hline \multicolumn{4}{|l|}{ Site } \\
\hline Right breast & 8 & 11 & \multirow{2}{*}{0.03} \\
\hline Left breast & 3 & 22 & \\
\hline \multicolumn{4}{|l|}{ SBR grade } \\
\hline I & 0 & 0 & \multirow{3}{*}{0.30} \\
\hline II & 0 & 5 & \\
\hline III & 11 & 28 & \\
\hline \multicolumn{4}{|l|}{ Tumor size } \\
\hline$<3 \mathrm{~cm}$ & 3 & 15 & \multirow{2}{*}{0.29} \\
\hline$>3 \mathrm{~cm}$ & 8 & 18 & \\
\hline \multicolumn{4}{|l|}{$\mathrm{T}$ stage } \\
\hline $\mathrm{T} 1$ & 1 & 3 & \multirow{4}{*}{ - } \\
\hline $\mathrm{T} 2$ & 4 & 19 & \\
\hline T3 & 3 & 2 & \\
\hline $\mathrm{T} 4$ & 3 & 9 & \\
\hline \multicolumn{4}{|l|}{$\mathrm{N}$ stage } \\
\hline No & 4 & 11 & \multirow{4}{*}{0.08} \\
\hline $\mathrm{N} 1$ & 1 & 8 & \\
\hline $\mathrm{N} 2$ & 3 & 1 & \\
\hline N3 & 0 & 2 & \\
\hline \multicolumn{4}{|l|}{ Metastasis (M) } \\
\hline Absent & 10 & 25 & \multirow{2}{*}{0.88} \\
\hline Present & 1 & 3 & \\
\hline Clinical stage & & & \\
\hline I & 1 & 1 & \\
\hline IIa & 1 & 9 & \\
\hline $\mathrm{IIb}$ & 5 & 9 & \\
\hline IIIa & 1 & 1 & 0.53 \\
\hline IIIb & 2 & 5 & 0.53 \\
\hline IV & 1 & 3 & \\
\hline Estrogen receptors & & & \\
\hline Positive & 0 & 3 & 054 \\
\hline Negative & 10 & 24 & 0.54 \\
\hline Progesterone receptors & & & \\
\hline Positive & 0 & 3 & 0.54 \\
\hline Negative & 10 & 24 & 0.54 \\
\hline HER 2 & & & \\
\hline Positive & 0 & 4 & 0.15 \\
\hline Negative & 8 & 14 & \\
\hline Evolving event & & & \\
\hline Yes & 6 & 18 & 075 \\
\hline No & 5 & 12 & 0.15 \\
\hline
\end{tabular}


Table 4. Overall survival and progression free survival according to different parameters.

\begin{tabular}{|c|c|c|c|c|}
\hline \multirow{2}{*}{ Variable } & \multicolumn{2}{|c|}{ Overall survival } & \multicolumn{2}{|c|}{ Progression free survival } \\
\hline & Average (months) & $\mathrm{p}$ & Average (months) & $\mathrm{p}$ \\
\hline \multicolumn{5}{|l|}{ Age } \\
\hline$<50$ years & 129.1 & \multirow{2}{*}{0.49} & 57.5 & \multirow{2}{*}{0.76} \\
\hline$>50$ years & 161.4 & & 104.6 & \\
\hline \multicolumn{5}{|l|}{ Menopause } \\
\hline Yes & 183.9 & \multirow{2}{*}{0.53} & 115.3 & \multirow{2}{*}{0.88} \\
\hline No & 107 & & 51.8 & \\
\hline \multicolumn{5}{|c|}{ Family history of cancer } \\
\hline Yes & 185.2 & \multirow{2}{*}{0.71} & 36.7 & \multirow{2}{*}{0.90} \\
\hline No & 105.2 & & 108.7 & \\
\hline \multicolumn{5}{|l|}{ Site } \\
\hline Right breast & 93.5 & \multirow{2}{*}{0.09} & 72.7 & \multirow{2}{*}{0.89} \\
\hline Left breast & 211.2 & & 106.3 & \\
\hline \multicolumn{5}{|l|}{ SBR grade } \\
\hline II & NA & \multirow{2}{*}{ NA } & 31.3 & \multirow{2}{*}{0.48} \\
\hline III & NA & & 110.8 & \\
\hline \multicolumn{5}{|c|}{ Intra-ductal component } \\
\hline Yes & 143.6 & \multirow{2}{*}{0.14} & 94 & \multirow{2}{*}{0.24} \\
\hline No & 147.1 & & 84.1 & \\
\hline \multicolumn{5}{|c|}{ Vascular emboli } \\
\hline Yes & 67.9 & 0.52 & 67.3 & 034 \\
\hline No & 181.8 & 0.52 & 96.1 & 0.34 \\
\hline Mesenchymal comp & & & & \\
\hline Yes & 118.2 & & 60 & \\
\hline No & 176.1 & 0.93 & 94.2 & 0.4 \\
\hline Tumor size & & & & \\
\hline$<3 \mathrm{~cm}$ & 128.8 & 04 & 52.7 & 0.63 \\
\hline$>3 \mathrm{~cm}$ & 172.6 & 0.4 & 114.3 & 0.63 \\
\hline T stage & & & & \\
\hline $\mathrm{T} 1-\mathrm{T} 2$ & 121.3 & 0.72 & 70 & 0.64 \\
\hline $\mathrm{T} 3-\mathrm{T} 4$ & 173.7 & 0.72 & 110.4 & 0.64 \\
\hline $\mathrm{pN}$ stage & & & & \\
\hline No & 143.4 & & 88.8 & \\
\hline N1 & 157.5 & & 147.3 & \\
\hline $\mathrm{N} 2$ & 24 & 0.001 & 15.7 & 0.002 \\
\hline N3 & 18.5 & & 7.5 & \\
\hline Lymph node meta & & & & \\
\hline Absent & 143.4 & 002 & 88.8 & 013 \\
\hline Present & 106.3 & 0.02 & 94.8 & 0.13 \\
\hline Clinical stage & & & & \\
\hline $\mathrm{I} / \mathrm{II}$ & 119.2 & 0.71 & 72.1 & 0.8 \\
\hline III/IV & 199.7 & $0 . / 1$ & 132.3 & \\
\hline Estrogen recept & & & & \\
\hline Positive & NA & NA & 55 & 0.35 \\
\hline Negative & NA & $\mathrm{NA}$ & 107.3 & 0.35 \\
\hline Progesterone rece & & & & \\
\hline Positive & NA & & 55 & \\
\hline Negative & NA & NA & 107.3 & 0.35 \\
\hline
\end{tabular}




\section{Continued}

\begin{tabular}{ccccc}
\hline HER 2 & & & & \\
Positive & NA & NA & 25.8 & 0.59 \\
Negative & NA & & 51.7 & \\
Triple negative & & & & \\
Yes & NA & NA & 46.8 & 0.59 \\
No & NA & N1.1 & \\
\hline
\end{tabular}

$\mathrm{NA}=$ not applicable.

Factors that significantly influenced OS and PFS were histological lymph node involvement, particularly the $\mathrm{pNstage}(\mathrm{p}=0.001$ and $\mathrm{p}=0.002$ respectively).

\section{Discussion}

Metaplastic carcinoma was reported for the first time more than 40 years ago [2], and it has been progressively described as a distinct entity of breast cancer [3]. But because of its rarity, only a few isolated cases and small series have been reported [4] [5] [6]. This rarity is confirmed by our work that concluded at a rate of $0.97 \%$ among all breast cancers archived in our cancer registry in central Tunisia for a period of 26 years.

The average age of metaplastic cancer occurrence varies between 45.5 and 63 years [1] [4] [5] [7] [8]. In our study, the average age at diagnosis was 55.4 years (range: 26 - 84) which is consistent with the literature.

Like all breast cancers, metaplastic carcinoma occurs almost exclusively in women. It is exceptionally found in men; only two cases are reported in the literature [8] [9]. No cases were found in our series.

These cancers often develop after menopause [1] [5]. This was confirmed in our series, as $61.4 \%$ of our patients were menopausal.

Family or personal history of breast cancer is a known risk factor. No published study has reported a history of metaplastic breast cancer. In our series, a history of breast cancer in first- and/or second-degree parents was found in $22.7 \%$ of cases, but the histological type was not specified.

In reviewing the literature and our study, no case was bilateral.

Our statistical study revealed a significant association between the presence of a mesenchymal component and the occurrence of metaplastic cancer in women at menopause $(\mathrm{p}=0.04)$. Another significant association was found between the presence of a mesenchymal component and the localization of cancer in the right breast $(\mathrm{p}=0.03)$. To our knowledge, no study was interested in these associations of mesenchymal metaplasia and the different clinical and pathological parameters studied.

Metaplastic carcinomas are characterized by their large size [10]; our study found an average tumor size at the time of diagnosis of $4.95 \mathrm{~cm}$. Our data are consistent with those from the recent literature [4] [5] [7] [8] [10], and the large size at diagnosis is related, most likely, to the potential for rapid growth and the aggressiveness of this entity. We note that some studies have reported that the 
initial tumor size is one of the best predictors of survival in metaplastic carcinoma [11].

Radiological aspects are not specific. Mammographic signs reported as suggestive are the mass hyperdensity and the absence of micro-calcifications [6] [11]. But mammography can sometimes be erroneous, and concluded at a phyllode tumor or fibroadenoma such as those reported by Yang et al. [12], and even three of our cases.

Breast ultrasound can show solid areas and other cystics that correspond to foci of necrosis, haemorrhage and/or cystic degeneration, hence the need to evoke the diagnosis of metaplastic carcinoma in front of a breast nodule with a cystic component. In our patients, we did not observe cystic forms as described in the literature [13].

Because of its low incidence and pathological variability, the ideal treatment paradigm for metaplastic carcinomas of the breast remains unknown [3]. The proposed therapeutic strategy is based on surgery. Conservative surgery is possible for small tumors and appropriate patients [3] [10] [14]. For larger tumors, mastectomy is indicated. For our patients, surgical treatment was proposed in more than $95 \%$ of cases, and was radical in $63.7 \%$ of cases because of the locally evolved nature of the disease.

All studies agree that the rate of axillary lymph node involvement is significantly lower in case of metaplastic carcinoma compared to other histological types of breast cancer dominated by invasive ductal carcinoma (ICC), which is another distinctive feature of this entity [4] [7] [9] [10]. Thus, the frequency of extension to axillary lymph nodes in case of metaplastic carcinoma does not exceed $31 \%$ [7]. At this point, our study is distinguished by a higher incidence of axillary lymph node involvement, since in $45.9 \%$ of the cases, ipsilateral lymphadenopathy was palpated clinically, and in $54 \%$ of lymph node metastases were histologically proven.

Indeed, Wargotz et al. [9] have shown that lymph node involvement depends on the subtype of metaplastic carcinoma, with a high attack rate for carcinosarcoma, and lower for sarcomatoid carcinoma. Moreover, in patients with carcinosarcoma, it is the carcinomatous component that most often metastasises.

In addition, lymph node metastases are the most negative prognostic factor in the evolution of this breast cancer [9] [10] [15] [16] [17]. This was confirmed by our study since among the different clinical and pathological elements studied, only histologically proven ganglionic invasion significantly influenced OS and PFS ( $\mathrm{p}=0.001$ and $\mathrm{p}=0.002$ respectively).

In short, and to answer the question-whether or not to make an axillary dissection in patients with metaplastic carcinoma yet it seems little lymphophilic, and in the light of these data, it seems reasonable to propose a sentinel lymph node biopsy and a complete total lymph node dissection only in case of necessity imposed by the positivity of the sentinel.

The statement of major histo-prognostic characters (factors) shows that our 
metaplastic cancers are mostly high-grade tumors (SBR III 89\%) and aggressive with a high frequency of axillary lymph node invasion and distant metastases (9\% M1 from the outset). Other histological data, namely tumor necrosis (63\%), vascular emboli (23\%), peri-nerve infiltration (4\%) and intra-ductal component (40\%) were generally similar to those described in the literature.

In IHC and like basal phenotype carcinomas, metaplastic cancers are in the vast majority of cases "triple negative" tumors [1] [15] [17] [18] [19]. In our study, for the cases that benefited from the three markers, this profile was found in $73 \%$ of cases $(19 / 26)$. HER2 receptor overexpression is rarely reported in metaplastic cancers and ranges from 5 to $15 \%$ of cases [7] [15] [16] [17]. Our results are consistent with these data, since overexpression of HER2 oncoprotein was observed in only $15 \%$ of cases. Furthermore and in agreement with the literature [15], our study did not reveal a statistically significant difference between the two groups of "triple negative" and "non-triple negative" metaplastic cancers concerning the main clinical and pathological parameters analyzed.

Most of our patients received chemotherapy (84\%), radiotherapy (48\%) and hormone therapy $(23 \%)$. In our series and according to the literature, metaplastic cancers respond poorly to chemotherapy since more than half of our cases had evolutionary events related to their disease. In fact, locoregional and/or distant recurrences in treated patients were observed in 23 cases, dominated by pulmonary and bone secondary locations.

There is little data on the prognosis of metaplastic breast cancer. Most studies suggest the aggressive nature of these tumors [1] [4] [5] [7] [19] [20]. Chao et al. reported that the duration of clinical symptoms, tumor size, lymph node status and TNM stage are important determinants of survival [21]. Gibson et al. reported that metaplastic breast carcinomas are often advanced and have a high risk of local recurrence, but at similar stage the prognosis would be similar to classical forms of breast adenocarcinoma [14].

Metaplastic cancers tend to metastasize especially through blood to the lungs and skeleton. The frequency of distant metastases varies between 3\% and 13\% [20] [22] [23]. In our study, we found a comparatively high rate of metastasis (19 patients, $43 \%$ had distant metastases including 4 at the time of diagnosis).

Overall survival (OS) in patients with metaplastic carcinoma would be shorter than other types of breast carcinoma [1] [4] [14] [24]. According to some studies, 5-year OS ranges from $49 \%$ to $68 \%$ [5] [20] [24]. In our series, OS was $63 \%$ at 5 years and $60 \%$ at 10 years and PFS was at 5 years and 10 years of $38 \%$ and $32 \%$, respectively.

\section{Limitation of the Study}

The retrospective nature of our study has the advantage of being able to include more medical observations with an already established diagnosis of a rather rare pathology. However, it has the disadvantage of a certain inaccuracy linked to the collection of the data necessary for the study. We must then articulate our re- 
search around available data and sometimes cannot know all parameters we want, which limits our results.

\section{Conclusion}

Our study suggests that metaplastic breast cancer in Tunisian women has an unfavorable prognosis which can be improved through a more adapted therapeutic strategy taking into account its chemo- and hormon-resistance. These histological features and clinical outcomes encourage us to provide intensive treatment and more personalized therapies. We hope our results and those of literature will help determine the most appropriate options for better management.

\section{Conflicts of Interest}

The authors declare no conflicts of interest regarding the publication of this paper.

\section{References}

[1] Gauchotte, G., Gauchotte, E., Bressenot, A., Verhaeghe, J.L., Guillemin, F., Leroux, A., et al. (2011) Les carcinomes métaplasiques du sein: une étude morphologique et immunohistochimique. Annales de Pathologie, 31, 18-27.

https://doi.org/10.1016/j.annpat.2010.10.007

[2] Huvos, A.G., Lucas Jr., J.C. and Foote Jr., F.W. (1973) Metaplastic Breast Carcinoma. Rare Form of Mammary Cancer. New York State Journal of Medicine, 73, 1078-1082.

[3] Shah, D.R., Tseng, W.H. and Martinez, S.R. (2012) Treatment Options for Metaplastic Breast Cancer. ISRN Oncology, 2012, Article ID: 706162. https://doi.org/10.5402/2012/706162

[4] Song, Y., Liu, X., Zhang, G., Song, H., Ren, Y., He, X., et al. (2013) Unique Clinicopathological Features of Metaplastic Breast Carcinoma Compared with Invasive Ductal Carcinoma and Poor Prognostic Indicators. World Journal of Surgical Oncology, 11, 129. https://doi.org/10.1186/1477-7819-11-129

[5] Esbah, O., Turkoz, F.P., Turker, I., Durnali, A., Ekinci, A.S., Bal, O., et al. (2012) Metaplastic Breast Carcinoma: Case Series and Review of the Literature. Asian Pacific Journal of Cancer Prevention, 13, 4645-4649. https://doi.org/10.7314/APJCP.2012.13.9.4645

[6] Günhan-Bilgen, I., Memiş, A., Üstün, E.E., Zekioglu, O. and Özdemir, N. (2002) Metaplastic Carcinoma of the Breast: Clinical, Mammographic, and Sonographic Findings with Histopathologic Correlation. American Journal of Roentgenology, 178, 1421-1425. https://doi.org/10.2214/ajr.178.6.1781421

[7] Park, H.S., Park, S., Kim, J.H., Lee, J.H., Choi, S.Y., Park, B.W., et al. (2010) Clinicopathologic Features and Outcomes of Metaplastic Breast Carcinoma: Comparison with Invasive Ductal Carcinoma of the Breast. Yonsei Medical Journal, 51, 864-869. https://doi.org/10.3349/ymj.2010.51.6.864

[8] Driss, M., Mrad, K., Dhouib, R., Sassi, S., Abbes, I., Charfi, L. and Ben Romdhane, K. (2004) Carcinome métaplasique du sein: étude anatomo-clinique d'une série de 13 cas. Annales de Pathologie, 24, 141. https://doi.org/10.1016/S0242-6498(04)94144-2 
[9] Wargotz, E.S., Deos, P.H. and Norris, H.J. (1989) Metaplastic Carcinomas of the Breast. II. Spindle Cell Carcinoma. Human Pathology, 20, 732-740. https://doi.org/10.1016/0046-8177(89)90065-8

[10] Pezzi, C.M., Patel-Parekh, L., Cole, K., Franko, J., Klimberg, V.S. and Bland, K. (2007) Characteristics and Treatment of Metaplastic Breast Cancer: Analysis of 892 Cases from the National Cancer Data Base. Annals of Surgical Oncology, 14, 166-173. https://doi.org/10.1245/s10434-006-9124-7

[11] Carter, M.R., Hornick, J.L., Lester, S. and Fletcher, C.D. (2006) Spindle Cell (Sarcomatoid) Carcinoma of the Breast: A Clinicopathologic and Immunohistochemical Analysis of 29 Cases. American Journal of Surgical Pathology, 30, 300-309. https://doi.org/10.1097/01.pas.0000184809.27735.a1

[12] Yang, W.T., Hennessy, B., Broglio, K., Mills, C., Sneige, N., Davis, W.G., et al. (2007) Imaging Differences in Metaplastic and Invasive Ductal Carcinomas of the Breast. American Journal of Roentgenology, 189, 1288-1293. https://doi.org/10.2214/AJR.07.2056

[13] Leddy, R., Irshad, A., Rumboldt, T., Cluver, A., Campbell, A. and Ackerman, S. (2012) Review of Metaplastic Carcinoma of the Breast: Imaging Findings and $\mathrm{Pa}$ thologic Features. Journal of Clinical Imaging Science, 2, 21. https://doi.org/10.4103/2156-7514.95435

[14] Gibson, G.R., Qian, D., Ku, J.K. and Lai, L.L. (2005) Metaplastic Breast Cancer: Clinical Features and Outcomes. The American Surgeon, 71, 725-730.

[15] Lim, K.H., Oh, D.Y., Chie, E.K., Han, W., Im, S.A., Kim, T.Y., et al. (2010) Metaplastic Breast Carcinoma: Clinicopathologic Features and Prognostic Value of Triple Negativity. Japanese Journal of Clinical Oncology, 40, 112-118. https://doi.org/10.1093/jjco/hyp139

[16] Tse, G.M., Tan, P.H., Putti, T.C., Lui, P.C., Chaiwun, B. and Law, B.K. (2006) Metaplastic Carcinoma of the Breast: A Clinicopathological Review. Journal of Clinical Pathology, 59, 1079-1083. https://doi.org/10.1136/jcp.2005.030536

[17] Nassar, A., Sookhan, N., Santisteban, M., Bryant, S.C., Boughey, J.C., Giorgadze, T., et al. (2010) Diagnostic Utility of Snail in Metaplastic Breast Carcinoma. Diagnostic Pathology, 5, 76. https://doi.org/10.1186/1746-1596-5-76

[18] Reis-Filho, J.S., Milanezi, F., Steele, D., Savage, K., Simpson, P.T., Nesland, J.M., et al. (2006) Metaplastic Breast Carcinomas Are Basal-Like Tumours. Histopathology, 49, 10-21. https://doi.org/10.1111/j.1365-2559.2006.02467.x

[19] Weigelt, B., Kreike, B. and Reis-Filho, J.S. (2009) Metaplastic Breast Carcinomas Are Basal-Like Breast Cancers: A Genomic Profiling Analysis. Breast Cancer Research and Treatment, 117, 273-280. https://doi.org/10.1007/s10549-008-0197-9

[20] Rayson, D., Adjei, A.A., Suman, V.J., Wold, L.E. and Ingle, J.N. (1999) Metaplastic Breast Cancer: Prognosis and Response to Systemic Therapy. Annals of Oncology, 10, 413-419. https://doi.org/10.1023/A:1008329910362

[21] Chao, T.C., Wang, C.S., Chen, S.C. and Chen, M.F. (1999) Metaplastic Carcinomas of the Breast. Journal of Surgical Oncology, 71, 220-225. https://doi.org/10.1002/(SICI)1096-9098(199908)71:4<220::AID-JSO3>3.0.CO;2-L

[22] Park, J.H., Han, W., Kim, S.W., Lee, J.E., Shin, H.J., Kim, S.W., et al. (2005) The Clinicopathologic Characteristics of 38 Metaplastic Carcinomas of the Breast. Journal of Breast Cancer, 8, 59-63. https://doi.org/10.4048/jbc.2005.8.2.59

[23] Gilbert, J.A., Goetz, M.P., Reynolds, C.A., Ingle, J.N., Giordano, K.F., Suman, V.J., et al. (2008) Molecular Analysis of Metaplastic Breast Carcinoma: High EGFR Copy Number via Aneusomy. Molecular Cancer Therapeutics, 7, 944-951. 


\section{https://doi.org/10.1158/1535-7163.MCT-07-0570}

[24] Luini, A., Aguilar, M., Gatti, G., Fasani, R., Botteri, E., Brito, J.A., et al. (2007) Metaplastic Carcinoma of the Breast, an Unusual Disease with Worse Prognosis: The Experience of the European Institute of Oncology and Review of the Literature. Breast Cancer Research and Treatment, 101, 349-353.

https://doi.org/10.1007/s10549-006-9301-1 